\title{
The First Class: Using Icebreakers to Facilitate Transition in a Tertiary Environment
}

\author{
Marie Kavanagh (Corresponding author) \\ Faculty of Business, University of Southern Queensland \\ PO Box 4196, Springfield Central, Queensland 4300, Australia \\ Tel: 61-7-3470-4514Ｅ-mail: kavanagh@usq.edu.au \\ Marilyn Clark-Murphy \\ Faculty of Business and Law, Edith Cowan University \\ 270 Joondalup Drive, Joondalup, Western Australia 6027, Australia \\ Tel: 61-8-6304-0000 E-mail: m.clarkmurphy@westnet.com.au \\ Leigh Wood \\ Faculty of Business and Economics, Macquarie University \\ Sydney, NSW 2109, Australia \\ Tel: 61-2-9850-4756 E-mail: leigh.wood@mq.edu.au
}

Received: February 1, $2011 \quad$ Accepted: February 23, $2011 \quad$ doi:10.5539/ass.v7n4p84

Support for this project was provided by the Australian Learning and Teaching Council, an initiative of the Australian Government Department of Education, Employment and Workplace Relations. The views expressed in this paper do not necessarily reflect the views of the Australian Learning and Teaching Council Ltd.

\begin{abstract}
Transitioning to university can be difficult and encompasses many changes. This paper is concerned with identifying how initial student experiences on campus can be enhanced in order to influence students' perception of university. Universities are now under pressure to develop in graduates a wide range of skills, and we highlight the fact that equal emphasis needs to be placed on successful academic and social integration. Research reflecting processes to develop the concept of "social support" and overcome the feeling of "not belonging" at university is scarce. In this paper the concept of icebreakers in the first weeks of student university experience is explored. Icebreakers can also be used as students move to new learning situations through their learning journey. We trialled icebreaking activities in a workshop program designed to facilitate student engagement and develop particular graduate skills. Practical examples from both across and within disciplines are provided. Comments from workshop participants highlight the outcomes of these activities and provide criteria for success.
\end{abstract}

Keywords: Icebreakers, Transition to University, Student experience, Business education

\section{Introduction}

Students enter university programs for disparate reasons (Batchelor, 2006; Briggs, 2006) with different expectations about what their experience is going to be like (Crisp et al., 2009; Kuh, Gonyea, \& Williams, 2005), and how they will spend their first year at university (Kuh \& Pace, 1999). In this paper we concentrate on the first interaction with students in a class setting with the use of "icebreaking" activities to create a vibrant, inclusive learning environment and develop enthusiasm in order to "hook" students into the university environment and discipline area. Icebreaking activities are designed to establish common ground in the first class, get students to introduce themselves to others and talk to others in a semi-structured "fun" environment. Effective delivery of the icebreaking session requires a competent facilitator (lecturer) who engages students in simple activities (for example, find someone who has a brother) in order to encourage students to interact. While 
these activities can be adapted to online environments, we will focus in this paper on face-to-face activities. As the time allowed for face-to-face learning continues to reduce into the future, the importance of the quality of face-to-face interaction and subsequent online interaction will increase further.

In this paper we will use the term "icebreaker" to cover activities designed to help students meet each other and transition to their new learning environment when they start at university or when they move to a new learning environment.

In all learning, more than content is being taught. We are inducting students into a discipline, a way of thinking and a way of working with others and understanding how they themselves prefer to work. We are working with knowledge and with people; both are important. We will consider the relationships between the student and teacher; student and student; and assist students to understand themselves. We will show how to develop and adapt icebreaking activities to introduce students to content areas, particularly in business.

Studies of first year students both in Australia and the UK (McInnis, James, \& Hartley, 2000; Trotter \& Roberts, 2006) suggest that the first class in first year is our opportunity to create a positive learning atmosphere for the rest of the semester - and perhaps the rest of a student's experience at university. Indeed the first year has been shown to be the most critical in shaping persistence decisions. While the experiences in our classrooms are influenced by external conditions such as the enrolment processes, expectations from peers, physical environment and so on, in this paper we concentrate on the learning conditions in the first classroom and introduce the concept of icebreakers as a means of easing the transition and enhancing outcomes for students.

\subsection{Learning environment - content}

The first class provides an opportunity to set expectations for learning in the subject: "The first class meeting is often a defining moment in a course: it establishes expectations and an implicit learning contract on the part of both students and lecturer." Holden $(2004$, p. 4) The first class also sets expectations for interaction - the classroom as a social as well as a learning place - and sets up conditions for the class to work productively.

Icebreakers assist the teacher to show enthusiasm about the content area and learning, and about the students themselves. One way to do this is to make a link with prerequisite knowledge and relate the content to what a student will be familiar with. Particularly in first year, it helps with learning if the lecturer describes links between the unit and the profession that a student may be working towards. Several studies show that students demonstrate a deeper learning approach if they are aware of the outcome of their learning (Wood \& Solomonides, 2008; Reid et al., 2005).

For students in later years, icebreakers can review content from previous study, for example:

-What were the three most important things you learned in (prerequisite subject)? Why?

- Knowledge gets rusty fast - why?

These quick icebreakers can lead into discussions about learning and how best to learn in your subject. At best it can lead to a discussion on the nature of knowledge in your discipline area.

\subsection{Learning environment - relationships}

The main relationships we will concentrate on in this paper are: the student-teacher; student-student; and the students learning about themselves. Developing relationships is an important part of learning: what all first sessions in a unit have in common is that they signify the beginning of a relationship between the teacher and students, and between student and student. How the session unfolds sets the pattern for later interactions (McKay, 2002).

With the reduction in the number of hours for face-to-face learning, we need to find ways to make connections between people quickly and effectively in large and small groups. Icebreakers are an effective way to create these connections and can contribute to a positive learning environment as well as introduce important content. Students will also make a judgement about their participation and whether it is safe for them to contribute: it is our role to set conditions where students will feel safe to take risks and actively participate in class activities. The use of icebreakers can also contribute to developing cultural awareness and tolerance, breaking down barriers, and overcoming isolation and loneliness.

\subsection{Alignment}

Design of curriculum involves many aspects: the learning materials, tasks, assessment and relationships. How do these align? To take an extreme example, our learning objectives may be to develop critical thinking and teamwork but our assessment tasks are all individual and require rote learning. Clearly the assessment and the 
learning objectives are not aligned. Students' every experience of the subject must give a consistent (aligned) message and this is established in the first class. Our use of icebreakers aligns with learning objectives that work to establish trust and participation in the community of scholars and set the scene for a collaborative learning environment.

The paper is structured as follows. The background to the study is discussed in section two. In section three, factors influencing the context (including the need to develop graduate attributes and skills) and the workshop are outlined. Section four presents examples of icebreaker activities, drawn primarily from the workshop designed to develop and assess the graduate skills of business students in Australia (www.graduateskills.edu.au), which was funded by the Australian Learning and Teaching Council (ALTC). In section five, the success of the icebreaking activities and student reactions as evidenced by quotes from the workshop participants are presented. A discussion of the process and outcomes concludes the paper.

\section{Background}

The transition to university and its challenges are well recognised (Krause et al., 2005; James, Krause, \& Jennings, 2010), highlighting the many changes required to shift into university environments of academic and student life (Harvey, Drew, \& Smith, 2006). There is sometimes a considerable difference between the students' expectations and the experience that institutions offer (Crisp et al., 2009). The first year experience may have significant consequences for student attrition and failure, in turn affecting university reputations and finances (Wilcox, Winn, \& Fyvie-Gauld, 2005). Expectations of what it will be like to be a university student play a determining role in student attitudes towards study and in the quality of their experience and achievement levels. James, Krause and Jennings (2010) found that the school-to-university transition appears to be improving in quality and half of the students felt that school is preparing them well for university. This was not the case, however, for students from rural areas and those from lower socio-economic backgrounds. The changing role of universities and the growing diversity of students entering universities have highlighted the ongoing demand for research into the first year transition process.

Studies of Australian first year students (McInnis, James, \& Hartley, 2000; Krause et al., 2005; James, Krause, \& Jennings, 2010) show that initial experiences on campus are important and influence students' persistence in higher education. There is also general agreement in the literature that a high proportion of students either withdraw or fail because of adjustment or environmental factors, rather than because of intellectual difficulties (Tinto, 1996). Pitkethly and Prosser (2001) suggest that a coordinated, informed response to transition issues will improve the learning experience of all first year students. Jamelski (2009) suggests that first year experience programs are essential and can have marked effects on student grade point averages (GPA) and retention. While it is easy to blame this new generation of students for falling retention rates, it is far more productive to concentrate on those issues that impact on retention and how we as academics can alter the environment that students encounter.

This is not only true in first year but in each new learning situation. Transitions are inherently challenging, as illuminated by the separation-transition-reincorporation phases identified by Bridges (2003). Separation is the move away from established beliefs and values; transition is the in-between stage where ambiguity may be experienced; and reincorporation is the stage where the individual becomes accepting of and accepted by the new context of being. Given the nature of each stage, it is hardly surprising that transition involves emotional challenges. Reid and Solomonides (2007, p. 31) describe students moving through "cognitive and emotional borders" as students focus their attention on different parts of their anticipated professional and internal life, depending on whether they focus on some future profession, or being a learner, or being a student at university.

Students' decisions to withdraw are significantly affected by the degree of their intellectual and social integration into the life of the institution (Krause et al., 2005; James, Krause, \& Jennings, 2010). The concept of "not belonging" is becoming a prevalent theme in accounts of the first year student experience at university (Palmer, Kane, \& Owens, 2009; Solomon, 2007). Crissman-Ishler and Schreiber (2002) examined students' experiences of "friendsickness" during the early phases of university life, while Johnson (1994) suggested that a student's psychological state is strongly associated with student withdrawal, and further that transition depends on how students rebuild friendship networks. Peat, Dalzeil and Grant (2001) found that a workshop to develop peer networks facilitated the formation of social networks and peer groups, which eased the transition to university. Wilcox, Winn and Fyvie-Gauld (2005) suggest that to improve higher education student retention, equal emphasis needs to be placed on successful integration into the social world of university as into the academic world, and that social ties, developed through living and associating with compatible friends, are central to the issue of transition. 
Students report a need for both physical and social opportunities, and spaces for making contact with others (social integration). For example, international students experience loneliness and adjustments to new learning situations; problems with contributing in class where language is difficult; wanting an international experience; and seeking opportunities and skills to be able to interact (Krause et al., 2005). This is particularly important given the growing number of first-generation students as well as a widening of the gap in relation to understanding the role of the university (Skyrme, 2007). Palmer, O'Kane and Owens (2009) discuss the concept of turning-point experiences in the transition process. They suggest that universities are now placing emphasis on dealing with issues such as creating a sense of community through increased social activities and opportunities - both with peer groups and other students - and involving students in university life in group projects or extra-curricula activities. These activities are designed to overcome students' feelings of not belonging to university life.

Research into graduates' reflections on their experience at university shows that many graduates would have appreciated an opportunity to meet with others in their class (Wood \& Reid, 2005). Our paper seeks to draw on the work of Solomon (2007) regarding the notion of not belonging, and Palmer, O'Kane and Owens' (2009) findings about the turning points that allow students to make meaningful connections to fit into university life.

\section{Context}

Recent shifts in education and labour market policy have resulted in universities being placed under increasing pressure to produce employable graduates with governments (particularly in the UK, Australia and Canada) making public funding for universities contingent upon demonstrable graduate outcomes. Employers now expect that graduates will commence employment with a broader range of attributes and vocational skills to complement their technical skills. As a result, universities have begun to focus on developing generic skills in students that might make them appealing to multiple employers across multiple work contexts and disciplines (Bridgstock, 2009). An emphasis has been placed on the production of "work-ready" graduates, competent in their disciplinary field and able to cope in a changing work environment (Barrie, 2006). Oliver (2008) observed that, "the attributes for success in commencing and advancing in a career and being an effective 'global citizen' are communication, teamwork, problem solving, self-management, planning and organising, technology, life-long learning, initiative, enterprise and the raft of skills generally called 'emotional intelligence'." (p. 1) In spite of the push to change the focus in terms of skills development in universities, the development of these skills has remained problematic (Green, Hammer, \& Star, 2009). For example, in a report compiled for the Council for Industry and Higher Education (CIHE) in the UK, Archer and Davison (2008) documented the fact that, despite $86 \%$ of employers considering good communication skills to be important, many are dissatisfied with the ability of graduates to express themselves effectively.

The need to incorporate the development of graduate skills becomes evident. An Australian Learning and Teaching Council (ALTC) grant was provided to seven universities to conduct a project titled "Embedding the Development and Grading of Generic Skills in the Business Curriculum" as part of a larger project to assess graduate skills (www.graduateskills.edu.au). A major activity of the project was holding a workshop with five students from each of the seven universities coming together to trial various deliverables of the project, including the icebreaker activities as well as case studies designed to enhance the expertise of the students in the skill areas of ethical practice, critical thinking, teamwork and sustainability. From that project the icebreaker examples listed in the next section have been refined as engagement activities. It is important to note that while these examples of activities are applicable to tertiary education in general, they have been developed and trialled in business education in Australia.

\section{Examples of icebreaker activities}

The principal purpose of icebreakers is to get students talking to each other about as many different aspects of their lives and backgrounds as possible. This obviously facilitates communication, but it also makes students aware of the similarities and differences among them. For example, in a class with a good mix of international students, the "siblings" exercise below will find most Chinese students in the "only child" group and many African students in the "or more" group. Icebreakers can also be targeted to achieve a specific purpose - for example, introducing group work - and can be made or designed to be discipline specific. Examples of all these activities are included. Wherever possible the lecturer should participate in the icebreakers, since the students need to feel at ease and get to know something about you. It is also an important means of understanding the demographics of your class and getting to know students individually. 


\subsection{Getting to know the group}

Ask students to form groups in a number of different ways. Then allow five minutes for discussion, after which they move to the next grouping. Make sure you give students time to introduce themselves within their groups before moving to the next. The groupings you choose should not be complex and should include things that students can easily relate to and that are relevant to both the students' personal life and their university life. Specifics will depend on the nature of your group but could include:

- Form a group with other students majoring in the same discipline as you.

- Are you studying full or part time? Form a group with others doing the same.

- Find all the students born in the same month as you.

- Point to the four walls of the room and tell students to gather on each wall based on certain criteria, for example:

$\circ$ Do you have a cat, a dog, both, neither.

$\circ$ Do you have no siblings, one, two, more.

$\circ$ Your ideal relaxation is reading, socialising with friends, gardening, sport.

These types of groupings can also be related to the content you are about to teach. For instance, in a marketing class you might ask students to group by specific brands; their favourite soft drink, the car they drive and so on. In a finance class you could group by usage of particular financial products or services. The complexity of the group "names" will depend on the knowledge level of the students and what they should be able to respond to.

- Pick a student born close to your current location, ask all other students to form a circle so that the next person born near to the current location is on the first student's right and the person born farthest from the current location is on the first student's left. This typically involves not only getting to know each other but some interesting conversations about geography!

- Find the individual - Everyone takes a piece of paper and writes down four or five adjectives to describe themselves. Papers are collected and redistributed at random. People must try and find the author of the paper they have been given by looking and asking questions. They then return the paper to its author. Keep going until everyone has their own paper back.

\subsection{Going deeper}

Depending on the size of your group and the time available, you may want to allow for some deeper conversations, for example the instructions for the activity could include:

- Interviewing

Students move around the room pairing up with people (one at a time) they do not know. On a sheet of paper in the middle write the name of the person they are interviewing. In each of the four corners write answers to the following:

a. What job they would love to do most.

b. The person in the world they would most like to meet and why.

c. The place in the world they would most like to live.

d. Something unusual or exciting about their lives they are willing to share with the group.

The interviewer asks questions of the other person to understand why.

The interviewer then introduces their partner to the group and reports what they have said.

- Form groups of four or five. Each person tells the group three things about themselves, two true and one false. Other members of the group have to guess which is false. Each group reports back to the whole group the true things they learned about each other and how good they were at spotting the falsehoods.

\subsection{Introducing group work}

If your teaching will involve the students in group work it is a good idea to introduce this early on in the unit, in an easy task with no consequences related to grading. There are many exercises that can be used and we outline a 
very simple one below. If you are taking a more advanced class you might want to use something related to the discipline that would remind students of the knowledge they should be bringing to the course.

\section{- Marooned}

Form groups of whatever size you plan to use in your course. As a group they must pick five items they would want to have if marooned on a desert island. They write their items on a large piece of paper and they must defend their list to the whole group.

\section{Success factors}

As with any program to engage students, careful consideration needs to be given to the design of the activities and the manner in which students are encouraged to engage in the activities. Using observations and feedback from the staff and students involved in the trial, the following factors have been identified as being essential to the success of using icebreakers in the classroom:

- Good facilitators

- Good activities - need to be conscious of expected audience and learning outcomes desired

- Time - need to allocate time to the activities; at least 40 minutes, but time well spent

- Space - can be done in almost any space where students have room to move around

- Link to learning-activities should be linked to the learning objectives of the class

- Example: using activities to introduce a marketing metrics class where you can introduce the types of variables that you are using; this could also be used in a consumer behaviour class.

- Example: using the distance from birthplace to allocate students to groups. This meets a learning objective of intercultural development that may be part of an international business curriculum.

- Follow up - in the next class the lecturer can refer back to the icebreakers.

\subsection{Student reactions}

Students commented that the icebreakers were important for setting the atmosphere in the class and conveying the expectations of the learning environment:

The first hour I think we did some introductory icebreaker type things and then learning, which set the environment and the atmosphere in the room and how, what we were learning about, so you were all meeting all these people and even though you're only making 30 seconds of contact and maybe you're learning two things about someone, it already begins to break down those barriers and those, you know, maybe insecure barriers of like trying to talk to people you don't know and trying to do work with people you don't know, and that's not even, like that doesn't even really occur in uni[versity].

Others commented that being able to relate to others and combine skills relevant to life in the real world is very important:

I think the university should be a total experience where it does grow a person not just like in a mental academic sort of way where they're just learning information. It should be ... that combination of different things because once you get into the real world then it is very much a mix of everything.

Participating students found that icebreakers helped them to recognise and acknowledge different personalities and the impact the combination of personalities has on group work and satisfaction. This is supported by the literature (Burdett \& Hastie, 2009):

The other thing was a lot of the students thought that at the very beginning the icebreakers were really effective. But I thought it was good to understand the different personalities of the students and that the tutor can pick those different characteristics up to group students together rather than expecting students to formulate their own groups.

The emergence of a need to understand the perspective and opinions of those from other cultures was another valuable insight provided by the icebreaker activities: 
All the icebreakers we had were so amazing. I thought coming over here would be [cool]; like interacting with different people from different cultures would be very difficult or not very pleasing for me. But as soon as I came over here, we had so many icebreakers. ... It was actually pretty good. Because you got around and you kind of talked to different people who you might not have talked to.

Overall the engagement and the sense of collaboration and even friendship which emerged from the icebreakers surprised the facilitators, who had underestimated the impact:

We were all strangers two days ago and we wouldn't have even looked at each other twice if we walked through the street and passed each other in the street and that sort of thing. Now it sort of feels like it's a real sort of mateship and friendship.

The dynamics of the whole group changed with students relaxing in one another's presence and becoming more focussed on the task at hand:

We had the icebreakers, we had all that, and I think a lot of cohesive ... this is built on humour and all that kind of stuff and able to feel relaxed. I mean, you need to feel relaxed to then be able to really function properly.

For many there was a sense of awe in terms of the change in group dynamics that eventuated. Even for those who had experienced group work at their own universities, the value of the icebreakers as a critical introduction to the group process became most evident:

Back at uni[versity], back at home it's sort of like you get into a group work and then you just sort of don't actually get to know each other and build those relationships. It's just like straight onto the task, and I think that's one of the detriments to the whole lack of uni culture now. It is very much you go do your thing, you get away, you get your mark.

\section{Conclusion}

This paper has examined the place of icebreakers in the transitioning process as students move to new learning situations. The focus on developing softer skills through social integration to assist students to develop feelings of belonging has been highlighted. The comments of students who took part in a workshop to trial icebreakers indicate that these activities may result in turning points, which can shape or alter the way in which students make meaningful connections with university life. The outcomes of this research support and add to the literature in showing that expectations align with levels of student satisfaction. Their early experience of learning and connections with the university are known to make or break persistence with their study thus impacting on retention and attrition. Therefore the process and activities outlined in this paper should have resonance and be of interest to all educators who are concerned with enhancing student outcomes, in particular those involved in easing students' transition to learning.

\section{References}

Archer, W., \& Davison, J. (2008). Graduate employability: the views of employers. London: The Council for Industry and Higher Education.

Barrie, S. C. (2006). Understanding what we mean by generic attributes of graduates. Higher Education, 51(2), 215-241.

Batchelor, D. (2006). Becoming what you want to be. London Review of Education, 4(3), 225-238.

Bridges, W. (2003). Managing transitions: making the most of change. New York: Perseus Publishing Ltd.

Bridgstock, R. (2009). The graduate attributes we've overlooked: enhancing graduate employability through career management skills. Higher Education Research \& Development, 28(1), 31-44.

Briggs, S. (2006). An exploratory study of the factors influencing undergraduate student choice: the case of higher education in Scotland. Studies in Higher Education, 31(6), 705-722.

Burdett, J. \& Hastie, B. (2009). Predicting satisfaction with group work assignments. Journal of University Teaching and Learning Practice, 6(1), 181-195.

Crisp, G., Palmer, E., Turnbull, D. Nettelbeck, T., Ward, L., LeCouteur, A., Sarris, A., Strelan, P., \& Schneider, L. (2009). First year student expectations: results from a university-wide student survey. Journal of University 
Teaching and Learning Practice, 6(1), 196-220.

Crissman-Ishler, J.L., \& Schreiber, S. (2002). First-year female students: perceptions of friendship. Journal of the First Year and Students in Transition, 14, 89-104.

Gibbs, G., \& Jenkins, A. (Eds.) (1992). Teaching large classes in higher education. London: Kogan Page.

Green, W., Hammer, S., \& Star, C. (2009). Facing up to the challenge: why is it so hard to develop graduate attributes? Higher Education Research and Development, 28(1), 17-29.

Harvey, L., Drew, S., \& Smith, M. (2006). The first-year experience: a review of literature for the Higher Education Academy. York, UK: Higher Education Academy.

Holden, P. (2004). Stimulating student interest in the first lecture. CDTL Brief, (7)6. [Online] Available: http://www.cdtl.nus.edu.sg/brief/V7n6/sec3.htm (January 26, 2011).

Jamelski, E. (2009). Measuring the impact of a university first-year experience e-program on student GPA and retention. Higher Education, 57, 373-391.

James, R., Krause, K.L., \& Jennings, C. (2010). The first year experience in Australian universities: findings from 1994 to 2009. Melbourne: Centre for the Study of Higher Education, The University of Melbourne.

Johnson, G.M. (1994). Undergraduate student attrition: a comparison of the characteristics of students who withdraw and students who persist. Alberta Journal of Educational Research, 40(3), 337-353.

Krause, K.L., Hartley, R., James, R., \& McInnis, C. (2005). The first year experience in Australian universities: findings from a decade of national studies. Australia: Department of Education Science and Training.

Kuh, G.D. \& Pace, C.R. (1999). College student expectations questionnaire (2nd ed.). Bloomington: Center for Postsecondary Research, Indiana University.

Kuh, G.D., Gonyea, R.M., \& Williams, J.M. (2005). What students expect from college and what they get. In T.E. Miller, B.E. Bender, \& J.H. Schuh \& Associates (Eds.), Promoting reasonable expectations: aligning student and institutional views of the college experience. San Francisco, CA: Jossey Bass.

McInnis, C., James, R., \& Hartley, R. (2000). Trends in the first year experience in Australian universities. Canberra: AGPS.

McKay, R. (2002). The lecture - the first one. University Centre for Teaching and Learning, Information Series, No. 300/14, University of Canterbury. [Online] Available: http://www.uctl.canterbury.ac.nz/info.shtml (January 26, 2011).

Oliver, B. (2008). Graduate employability as a standard of success in teaching and learning. Australian Universities Quality Forum, [Online] Canberra. Available: http:/www.auqa.edu.au/auqf/pastfora/2008/program/papers/d8.pdf (January 26, 2011).

Palmer, M., O’Kane, P., \& Owens, M. (2009). Betwixt spaces: student accounts of turning point experiences in the first-year transition, Studies in Higher Education, 34(1), 37-54.

Peat, M., Dalzeil, J., \& Grant, A.M. (2001). Enhancing the first-year student experience by facilitation: the development of peer networks through a one-day workshop. Higher Education Research and Development, 20(2), 199-215.

Pitkethly, A. \& Prosser, M. (2001). The first-year experience project: a model for university-wide change. Higher Education Research and Development, 20(2), 185-198.

Reid, A. \& Solomonides, I. (2007). Design students' experience of engagement and creativity. Art Design and Communication in Higher Education, 6(1), 27-39.

Reid, A., Wood, L.N., Smith, G.H., \& Petocz, P. (2005). Intention, approach and outcome: university mathematics students' conceptions of learning mathematics. International Journal of Science and Mathematics Education, 3(4), 567-586.

Skyrme, G. (2007). Entering the university: the differentiated experience of two Chinese international students in a New Zealand university, Studies in Higher Education, 32, 357-72. 
Solomon, Y. (2007). Not belonging? What makes a functional learner identity in undergraduate mathematics? Studies in Higher Education, 32, 79-96.

Tinto, V. (1996). Reconstructing the first year of college. Planning for Higher Education, 25(1), 1-6.

Trotter, E. \& Roberts, C.A. (2006). Enhancing the early student experience. Higher Education Research and Development, 25(4), 371-386.

Wilcox, P., Winn, S., \& Fyvie-Gauld, M. (2005). It was nothing to do with the university, it was just the people: the role of social support in the first-year experience of higher education. Studies in Higher Education, 30, 707-722.

Wood, L.N. \& Solomonides, I. (2008). Different disciplines, different transitions. Mathematics Education Research Journal. 20(2), 117-134.

Wood, L.N., \& Reid, A. (2005). Graduates' initial experiences of work. In P.L. Jeffrey (Ed.), AARE 2004 Conference - Papers Collection. Melbourne, Victoria: The Australian Association for Research in Education. [Online] Available: http://www/aare.edu.au/05pap/woo05147.pdf (January 26, 2011). 